\title{
The Study of the Actual Fears Structure of Children and Their Mothers
}

\author{
Aida F. Minullina ${ }^{1}$, Ilsiyar A. Akramova ${ }^{1} \&$ Olga A. Gurianova ${ }^{1}$ \\ ${ }^{1}$ Kazan (Volga region) Federal University, Kazan, Russia \\ Correspondence: Aida F. Minullina, Kazan (Volga region) Federal University, Kremlyovskaya Street 18, Kazan, \\ 420008, Russia. E-mail: aidamin@rambler.ru
}

Received: January 19, 2014 Accepted: February 22, 2015 Online Published: March 30, 2015

doi:10.5539/res.v7n5p244 URL: http://dx.doi.org/10.5539/res.v7n5p244

\begin{abstract}
The significance of the research is determined by importance of relationship of a child with a close adult for his personality forming. The article deals with the study of actual fears structure of children and their mothers. It reveals actual fears of women leaders and those of their primary school age children. Besides, the article determines the presence and specificity of the connections between the actual fears of the women leaders and the actual fears of their primary school age children, and the parental relationship features. The article can be useful in psychological and pedagogical practice.
\end{abstract}

Keywords: actual fears, primary school age children, parental relationship features

\section{Introduction}

Scientific and psychological study of fear, as well as emotional phenomena, in general, originates from Charles Darwin's work "The expression of the emotions in man and animals". It is well known that his views on fear are based on two main propositions: firstly, the ability to experience fear, as an innate feature of human and animal, plays the significant role in the process of natural selection; secondly, the fact that through many generations this adaptive mechanism was developed, since the one who was the most skillful at avoiding and overcoming danger, defeated and survived (Mironenko, 1977). A number of such conceptions of psychological science as psychoanalysis, Gestalt, behaviorism, etc. have common features with Darwin's theory.

The issue of the adult people's fears was first raised and specifically examined in the works of Freud, Hinshelwood, was studied within the learning theory (Watson et al.), in humanistic theories (Husserl, Sartre, Jaspers, Perls, etc.).

According to Freud, fear is the affect, the unification of certain sensations of pleasure or displeasure with the corresponding relaxation innervations and the perception of them, as well as, perhaps, the reflection of a particular significant event. In a state of mostly neurotic fear the reproduction of the birth trauma may be discovered. The only concentration point of fear is the Ego. Usually fear of a specific object acts as a dread, while acting as phobias in pathological cases (Icke, 1998).

Another representative of dynamic psychology, W. McDougall proposed understanding of the fear as an instinct. He reckoned the instinct of fear to be corresponded to such type of instrumental activity as an escape (Icke, 1998).

Examination of fear as a fundamental and innate emotion found its fullest expression in the works of J. Watson, the behaviorism founder, who also attributed anger and love, as well as fear, to the number of primary emotions. The problem of innate basic emotions with fear above all was widely discussed in the psychological publishing at the turn of the century, but the vestiges of the debates have not faded even now (Chirkina, 2015). The problem of fear in humanistic theories plays an important role. In this way representatives of existential psychology, psychotherapy and philosophy (Husserl, Sartre, Heidegger, Jaspers, and others) regard fear as one of the principal manifestations of human existence (being), along with care, commitment, conscience, guilt, love (Martynenko, 2003). Thus, in the scientific researches fear has a negative meaning as a neurosis developing factor, as well as positive - as an attribute of growth and personal development.

A huge contribution to the solution development and description of children's fear problem was made by Zakharov (1998, 2005), Prikhozhan (2000), Martynenko (2003), Astapov (2004) and other researchers (Barbarisova \& Shagivaleeva, 2013; Minullina, Murtazina, \& Konyashina, 2014). 


\section{Materials and Methods}

The study involved second grade students of Public educational institutions of Kazan, and their mothers (women in executive positions). The total number of respondents was 54 people including 27 children (16 boys and 11 girls) and 27 mothers at the average age of 29-36 years.

The study was conducted with the use of the following methods and techniques: 1) observation of emotional reactions, statements and actions of the ratees during the diagnostic procedures; 2) conversation with respondents in order to clarify, complement and analyze the information obtained during the application of projective techniques; 3) testing with the help of techniques as follows: The questionnaire on the hierarchical structure of actual fears of a personality by Shcherbatykh and Ivlev (Karelin, 2001); methods described in "Fears in the little houses by Zakharov and Panfilov (Panfilov, 1999); PARI techniques (parental attitude research instrument-a method of the parental attitude analyzing) by Schaefer and Bell, adapted by Neshcheret (Karelin, 2001); 4) mathematical methods of data processing: calculation of the average figure, the method of linear correlation analysis by Pearson.

\section{Results}

This research aimed to study the structure and interrelation of actual fears of mothers (women managers) and their children. The hypothesis put forward was following: the relationship of actual fears of mothers (women leaders) and their children is mediated by the characteristics of parental attitude.

The study of maternal fears. The research results are represented in the Table 1. Mothers are mostly subject to fear of close people's illness, fear of criminality, war, and fear of depth. It should be mentioned that the same fears are represented abundantly in children results sample. This is connected to a high level of responsibility and awareness of the maternal position.

The least apparent among the mothers are fears of the dark, fear of suicide, fears associated with sexual function and fear of public speaking. This is caused by the parent's personality being build up and socially orientated. Perhaps comparatively low figures of "fear of public speaking" scale are related to the fact that the mothers that participated in the study are managers of the top, the middle and the lower level. Their daily professional activities are related to continuous communication with people, performances and meetings. The correlation analysis revealed the following relations:

1) The fear of the negative consequences of close people's illnesses, and fear of the authorities ( $r=0.45$ at $p \leq$ 0.05). It is known that the negative consequences of close people's illnesses affect family life in general. Mothers are anxious about the importance of spending much time with the sick person during and after the disease. Therefore, their career is to suffer, their duties are not going to be fully performed which actualizes their fear of the authorities.

Table 1. The mothers' (average) and their children's actual fears degree (in \%)

\begin{tabular}{lllll}
\hline No & $\begin{array}{l}\text { Mothers' fears } \\
\text { (The hierarchical structure of actual } \\
\text { fears of a personality questionnaire by } \\
\text { Yu. Shcherbatykh and E. Ivlev) }\end{array}$ & $\begin{array}{l}\text { Average } \\
\text { values }\end{array}$ & $\begin{array}{l}\text { Children's fears } \\
\text { (“Fears in the little houses» technique) }\end{array}$ & $\begin{array}{l}\text { Degree } \\
\text { (in \%) }\end{array}$ \\
\hline 1 & Fear of spiders and snakes & 55.74 & Staying alone & 33.33 \\
2 & Fear of the dark & 3.12 & Being attacked & 81.50 \\
3 & Fear of insanity & 4.39 & Falling ill/ being infected & 51.91 \\
4 & Fear of close people's illness & 8.51 & Dying & 98.91 \\
5 & Fear of criminality & 7.13 & Parents' death & 92.64 \\
6 & Fear of authorities & 5.14 & Some children & 14.81 \\
7 & Fear of changes in the private life & 5.88 & Some people & 51.92 \\
8 & Fear of responsibility & 5.80 & Mother or father & 22.21 \\
9 & Fear of old age & 4.86 & Parent's punishment & 48.14 \\
10 & Fear of heart attack & 4.33 & Fairy tale characters & 22.18 \\
\hline
\end{tabular}




\begin{tabular}{lllll}
\hline 11 & Fear of poverty & 5.34 & Before falling asleep & 14.79 \\
12 & Fear of the future & 5.56 & Nightmares & 59.26 \\
13 & "Exam" fear & 4.51 & The dark & 25.88 \\
14 & Fear of war & 6.03 & Animals & 55.49 \\
15 & Fear of death & 4.19 & Transport & 40.71 \\
16 & Fear of confined spaces & 5.93 & Elements & 44.44 \\
17 & Fear of heights. & 5.31 & Heights & 44.37 \\
18 & Fear of depth & 6.25 & Depth & 74.14 \\
19 & Fear of negative consequences of & 6.40 & Confined spaces & 44.36 \\
& close people's illnesses & & \\
20 & Fear of disease & 5.36 & Water & 25.89 \\
21 & Fear associated with sexual function & 2.74 & Flame & 70.42 \\
22 & Fear of suicide & 1.52 & Fire & 77.71 \\
23 & Fear of public speaking & 4.12 & War & 70.35 \\
24 & Fear of being aggressive to close & 4.59 & Broad streets, squares & 25.88 \\
& people & & & \\
25 & & & Doctors (not dentists) & 25.94 \\
26 & & & Blood & 37.04 \\
27 & & & Injections & 25.87 \\
28 & & & Pain & 48.14 \\
29 & & & Unexpected affect & 40.73 \\
30 & & & Being late for school & 55.45 \\
\hline
\end{tabular}

2) Fear of criminality and fear of changes in private life $(r=0.44$ at $p \leq 0.05)$. It is possible that mothers are afraid of crime in relation to them, and experience anxiety over the possibility of criminal acts in respect of their inner circle. Any crime is inevitably accompanied with changes in all spheres of life, including private live. Therefore, the more the mothers are afraid of crime, the more they are afraid of possible changes in the personal sphere.

3) Most mothers have fear of future. This fear correlates directly with fears of war $(r=0.50$ at $p \leq 0.05)$, death ( $r$ $=0.49$ at $p \leq 0.05)$, negative consequences of the close people's illnesses $(r=0.58$ at $p \leq 0.05)$ and aggression towards family $(\mathrm{r}=0.44$ at $\mathrm{p} \leq 0.05)$. All of the above, one way or another, entails changes in the future life.

4) War is seen as a security threat in all aspects. This may explain the actual fear of war among mothers, in conjunction with fear of death $(r=0.43$ at $p \leq 0.05)$, fear of negative consequences of the close people's illnesses $(\mathrm{r}=0.63$ at $\mathrm{p} \leq 0.05)$, fear of disease $(\mathrm{r}=0.53$ at $\mathrm{p} \leq 0.05)$.

5) Fear of depths and fear of public speaking $(r=0.48$ at $p \leq 0.05)$. Most fears problems researchers agree that the fear of depth is interpreted as a fear to sink, to drown, to be in an inevitable "dead end", to lose support (Zakharov, 1986, 2005; Martynenko, 2003). This is related to the fact that the process of dipping in the water and fear of public speaking has similar symptoms, namely choking, shortness of breath, loss of support, inability to influence the situation, loss of control over the event.

6) Fear of insanity and fears of changes in private life ( $r=0.47$ at $p \leq 0.05)$, old age $(r=0.60$ at $p \leq 0.05)$, war ( $r$ $=0.61$ at $p \leq 0.05)$, negative consequences of the close people illnesses $(r=0.47$ at $p \leq 0.05)$, getting sick / getting infected $(\mathrm{r}=0.42$ at $\mathrm{p} \leq 0.05)$. All aforementioned fears often lead to irreversible consequences. The leaders activity dynamics and the rapid change of events are usually controlled and planned by the woman herself, whereas the said actual fears are not subject to control, they cause the greatest concern.

7) Fear of the dark and fear of old age ( $r=0.48$ at $p \leq 0.05)$, and fear of changes in private life $(r=0.41$ at $p \leq$ 0.05). The fear of the dark is the fear of uncertainty: uncertain and unknown things are scaring. Old age is perhaps one of the most uncertain phenomena in human life for the one under this period. 
8) Fear of poverty and fear of the future $(r=0.39$ at $p \leq 0.05)$. Mothers are afraid of the possible inconsistency between their financial position and the contemporary needs of life; therefore, they are afraid of uncertainty in the future.

9) The sense of responsibility imposes the burden of worries and emotional experience on a person. Our study shows that the more the fear of responsibility is developed, the more fears for the heart $(r=0.43$ at $p \leq 0.05)$, the future $(r=0.57$ at $p \leq 0.05)$ and death $(r=0.52$ at $p \leq 0.05)$ show.

10) Logical is the fact that the more intensive the fear of death is, the more fears of close people's illnesses' negative consequences $(r=0.48$ at $p \leq 0.05)$, fear of aggression towards family $(r=0.48$ at $p \leq 0.05)$ are going to be expressed. Death, as being the most powerful destructive instinct, is inextricably linked with aggression and disease.

11) The disease can make significant adjustments in the dynamic life of a woman leader. The disease of the mother, of course, will affect her career. The aggression towards family can be displayed due to failure in work ( $\mathrm{r}$ $=0.40$ at $\mathrm{p} \leq 0.05$ ).

According to Zakharov, all kinds of fears that are associated with diseases, disease impacts, affects, represent the transformed fear of death, which has an egocentric direction and is connected with self-preservation instinct (Zakharov, 1986, 2005). The women leaders have much more powerful transformation of this fear to be compared with women who are not on the executive position. This is determined by the intensive dynamic life of women holding a leading position. A high level of moral and finance responsibility, active lifestyle, risky situations lead to a strong transformation of fear.

The study of children's fears. The results obtained are presented in Table 1. The children are mostly subject to fears of death and the death of his parents. This is determined by the fact that exactly at this age (8-9 years) children's egocentric orientation of the personality is replaced by the sociocentric orientation - the fear of his/her own death is transformed into the fear of the parents' death. During schooling children master the social position of pupils, their sense of responsibility and duty increase, obligations form, and all that contributes to the more active development of moral identity. Then, by the degree of expression, follow the fears of attack, flame, fire, war, and fear of depth. According to Zakharov, all of these fears are nothing but the transformed fear of death, his/her own death, which is egocentric and instinctively driven. By the primary school age these fears transform into the aforementioned socially mediated fears (Zakharov, 2005).

The least expressed ones are fears of fairy-tale characters, fear of falling asleep, fear of parents and fear of other children. "Fear of other children" is one of the least shown in this sample. It is probably caused by the fact that the child establishes the contacts with peers in the second year of schooling. This age period is sensitive to the adjustment of social contacts in the peer group. Fears of the dark, fear of loneliness, fear of confined space are represented rather poorly. According to Zakharov, this fears triad is typical for children of preschool age (Zakharov, 1986). Besides, a relatively small number of children are exposed to fear of water, medical fears, and the fear of large open spaces. The conducted correlation analysis showed the presence of proved relationship between actual fears.

1) Fear of attack and the fear of being late $(r=-0.43$ at $p \leq 0.05)$. It can be assumed that the fear of attack is instinctive and egocentrically directed while anxiety of late has the sociocentric orientation. Therefore, the higher the instinctive fear is, the less the fears of violation of social norms are expressed.

2) Children's fear of animals and fear of closed space $(r=0.50$ at $p \leq 0.05)$. As asserted by Zakharov, fear of animals is interpreted as the child's dread of inability to influence a certain animal in case of meeting (Zakharov, 1986). Similar feelings arise in children in a confined space, i.e., the inability to influence the situation or change it.

3) Fear of depths and a fear of confined space $(r=0.53$ at $p \leq 0.05)$, fears of fire $(r=0.50$ at $p \leq 0.05)$, blood $(r=$ 0.45 at $p \leq 0.05)$, pain $(r=0.44$ at $p \leq 0.05)$, unexpected affect $(r=0.49$ at $p \leq 0.05)$. This is explained by the fact that the depth is kind of the same enclosed space, presented in a different form. Therefore, the more the child is afraid of the depth, the more he/she is going to be afraid of confined spaces. According to Zakharov, depth is identified with water, a kind of despair, a threat to the health and prosperous existence. This can explain the relationship of fear of depth with a number of events that result in a direct threat to thriving (Zakharov, 2005).

4) Fear of flame and fear of fire ( $r=0.63$ at $p \leq 0.05)$, fear of open spaces $(r=0.38$ at $p \leq 0.05)$ and unexpected affect $(\mathrm{r}=0.54$ at $\mathrm{p} \leq 0.05)$. The fire can be seen as an unexpected threat or impact. The presence of fear of open spaces, according to Zakharov, suggests that the child is afraid to be vulnerable, unable to control the situation (Zakharov, 2005). In addition, the foregoing fears, as well as fear of being late $(r=0.40$ at $p \leq 0.05)$ are social 
fears, and there is an undeniable relationship between them.

5) Fear of nightmares and fears of war $(r=0.45$ at $p \leq 0.05)$, height $(r=0.49$ at $p \leq 0.05)$, injections $(r=0.42$ at $\mathrm{p} \leq 0.05$ ), which are likely to have harmful effects. All these fears don't have any specific subject and are accompanied with anxious feelings. Unable to be shown, they find their expression in dreams.

6) Fear of people and fear of unexpected affects $(r=0.50$ at $p \leq 0.05)$, fear of pain $(r=0.41$ at $p \leq 0.05)$. People are possible to cause impact and pain. In these cases, the fear of depth $(r=0.44$ at $p \leq 0.05)$ and confined spaces $(r=0.41$ at $p \leq 0.05)$, similarly, is directly linked to the fear of people. Fear of people has an inverse correlation with fear to fall asleep $(r=-0.43$ at $p \leq 0.05)$. Children may be afraid to die in their sleep being deprived thereby of social contacts and interaction.

7) Younger schoolchildren's fear of disease or any infection and fear of elements $(r=0.71$ at $p \leq 0.05)$, fear of heights $(\mathrm{r}=0.56$ at $\mathrm{p} \leq 0.05)$. Both element and war lead to the inevitable negative consequences, as well as a disease. Negative consequences also include death.

8) Fear of mother or father and fear of war $(r=-0.43$ at $\leq 0.05)$. The most terrible and devastating for a child is a life values crash. It can be assumed that when a child is afraid of the parents, or feels scared of the family and significant people, all other fears become less relevant.

9) Fear of punishment and fear of injections $(r=0.44$ at $p \leq 0.05)$, fear of unexpected affects $(r=0.41$ at $p \leq 0.05)$. Fear of punishment is displayed rather widely among children; around $50 \%$ of primary school children have it. It is possible that punishment, as a rule, is sudden and difficult to be predicted by a child. Therefore, the more fear of punishment shows, the more fears of unexpected affects and injections will be displayed.

10) Fear of the dark and fears of transport $(r=0.71$ at $p \leq 0.05)$, height $(r=0.49$ at $p \leq 0.05)$, injections $(r=0.42$ at $p$ 0.05). It is known that children of primary school age are not afraid of the darkness but of what is hidden in it. Moreover, it is the existing possibility of influence that can be exerted on the child in the dark that causes fear. All of the fears stated are connected with the possible impact that can cause death at worst. Thus, the child is afraid of the dark as the uncertainty and the associated fear of death, which is expressed in the fears of transport, war, injections as an unexpected affect.

The study of the parental attitude characteristics. The results obtained are presented in Table 2 .

The most evident signs of educational tactics of mothers are "self-sacrifice", "parental authority", "dependent mother" "child's activity". It can be assumed that in many cases families are not nuclear but extended. Hence, in one way or other, the autonomy of the mother is influenced by the people of the older generation, thereby drowning out every initiative actions display of the mother, as well as her implementation of mistress role. Other people often function as mother and housewife, especially considering the executive position of the respondents. Probably due to this, mother changes her educational tactics towards child. Less apparent characteristics are following: "dissatisfaction with the mistress role", "suppression of aggression", "excessive care, petulance". The mothers that participated in the study were of senior, middle and lower management levels. Their professional activity takes considerably more time than the work associated with a lower level of responsibility. Therefore, less time is given to the education of children, and part of the responsibilities for the upbringing of the child is transferred to other family members. Lack of time is compensated by the mother's excessive intervention to the child's inner world, as well as the desire to accelerate the process of the child's growing by any means possible.

Table 2. Average values according to the PARI technique (mother)

\begin{tabular}{llc}
\hline No & Features & $\begin{array}{l}\text { Average } \\
\text { value. }\end{array}$ \\
\hline 1 & Verbalization & 14.91 \\
2 & Excessive care & 13.48 \\
3 & Dependence on the family & 14.57 \\
4 & Will suppression & 15.03 \\
5 & Sense of self-sacrifice & 15.54 \\
6 & Fear to offend & 15.67 \\
7 & Family conflicts & 13.61 \\
\hline
\end{tabular}




\begin{tabular}{lll}
\hline 8 & Petulance & 13.02 \\
9 & Excessive rigor & 11.06 \\
10 & The exception of intrafamilial influences & 14.79 \\
11 & Superior authority of parents & 16.72 \\
12 & Suppression of aggression & 12.86 \\
13 & dissatisfaction with the mistress role & 11.84 \\
14 & Partner relationships & 15.13 \\
15 & Development of the child's activity & 15.77 \\
16 & Conflict avoidance & 12.22 \\
17 & Detachment of the husband & 14.35 \\
18 & Sexuality suppression & 13.68 \\
19 & Dominating mother & 15.5 \\
20 & Excessive intervention to the child's inner world & 15.56 \\
21 & Adjusted relationships & 16.93 \\
22 & Desire to accelerate the process of the child's growing & 14.11 \\
23 & Dependent mother & 16.14 \\
\hline
\end{tabular}

The analysis of the relationship between actual fear of mothers and their children and the parental relationship. The correlation analysis which was conducted, between the studied indicators presented the proved relations of:

1) "Exam" fear and installation will suppression $(r=0.48$ at $p \leq 0.05)$, children fear of heights $(r=-0.38$ at $p \leq$ 0.05). "Exam" fear is interpreted as a fear of control, fear of negative evaluation, fear of the "social failure". This fear is expressed in a mother's attitude towards suppressing the resistance, i.e. the will suppressing. Perhaps by this attitude, mothers suppress every manifestation of physical and mental activity of a child's, his/her independence, and they do not develop will-connected sphere of their children's personality. And as a result, even an instinctive fear of death transformed into a fear of heights, fades into the background and becomes less significant. In other words, this parental attitude has great significance and exceptional role of positive social evaluation for a child.

2) An attitude of "a sense of self-sacrifice in the role of mother" and a child's fear of parents' death ( $r=0.42$ at $p$ $\leq 0.05)$. Mother's fear for the heart and a parental attitude of "the feeling of sacrifice" $(r=0.47$ at $p \leq 0.05)$. During the upbringing, mothers in a variety of ways show their own fears to their children, and it forms an apparent fear of the parent's death. Thus, we can conclude that the higher the mother's fear for her heart is, the more her sense of maternal self-sacrifice is, as it is implemented in the upbringing process. This in its turn can shape a child's fear of losing their parents.

3) Maternal actual fears, such as fear of responsibility ( $r=0.52$ at $p \leq 0.05)$, fear of the future ( $r=0.46$ at $p \leq$ $0.05)$, fear for the heart $(r=0.43$ at $p \leq 0.05)$, fear of death $(r=0.51$ at $p \leq 0.05)$ and parental attitude of "family conflicts". Therefore, the more transparent these types of parents' fears are, the more evident family conflicts become both in the process of child upbringing, and family relationships in general. Because of conflict in the family, the child feels the constant uncertainty and emotional instability, which find the expression in the fear of nightmares that the child identifies with something that cannot be affected, as well as with something negative that happens against his will. Exactly the same way a child perceives conflict in family relationships. According to that and under such circumstances children are more afraid of war and the collapse of all around $(\mathrm{r}=0.42$ at $\mathrm{p}$ $\leq 0.05 ; \mathrm{r}=0.47$ at $\mathrm{p} \leq 0.05$ ).

4) Maternal actual fear of death and attitude of "unnecessary rigor" ( $r=0.39$ at $p \leq 0.05)$. Permanent restrictions in upbringing, sternness, rigidity lead to the formation of the large amount of actual fears such as: fear of an illness, any infection $(r=0.41$ at $p \leq 0.05)$, fear of transport $(r=0.52$ at $p \leq 0.05)$, height $(r=0,42$ at $p \leq 0.05)$, open space $(r=0,39$ at $p \leq 0.05)$. This can be explained with the fact that mothers' fear of death is expressed in constant anxiety for the child and for his/her safety. The desire of mothers to discipline and to organize the child, their endless prohibitions, sternness and strictness lead to the child's transformed fear of death expressed in the fears of heights, transport, diseases that result in a sense of insecurity and so called " nakedness". 
5) Fears of mothers (women leaders) as follows: of war $(r=0.53$ at $p \leq 0.05)$, death $(r=0.41$ at $p \leq 0.05)$, the negative consequences of close people's illness $(r=0.46$ at $p \leq 0.05)$ and attitude towards "suppression of the child's aggressiveness". War and death are results of aggression. Mothers, who have experienced the aforementioned fears, seek to bring their children up while suppressing these feelings. They apprehend the negative consequences that the aggression can entail. The child is taught that every manifestation of aggression is accompanied with negative results and destruction. This explains the relation between the mother's attitude towards the suppression of aggressiveness and children's fears of elements $(r=0.47$ at $p \leq 0.05)$, loneliness $(r=-$ 0.39 at $\mathrm{p} \leq 0.05$ ). Perhaps the mothers suppressing aggressiveness of the child (it is known that this position relates to the sign of being concentrated on the child) aim to form a loyal and tolerant attitude to people and to develop communication skills at their children. Fear of poverty featuring the "suppression of aggression" attitude has an inverse correlation $(\mathrm{r}=-0.53$ at $\mathrm{p} \leq 0.05)$ as the above-listed actual fears are biological by nature, and the fear of poverty is still socially determined. Having this type of fear, the women are less likely to suppress aggression in the child, and their potential will be aimed at eliminating possible material disadvantage.

6) Fear of responsibility and «dissatisfaction with the mistress role" ( $r=0.54$ at $p \leq 0.05)$, fear for the heart $(\mathrm{r}=$ 0.49 at $p \leq 0.05$ ). If a mother has a fear of responsibility as an actual fear, it is logical to assume that the woman avoids any kind of responsibility. The role of the house mistress provides a high level of responsibility for the family life organization. Fear for heart is a transformed fear of death. If the mother fears for her heart, she avoids heavy duties of various kinds, including those associated with household activity. If a woman is not satisfied with herself as a mistress, it is easy to assume that the family life is not quite well-organized. Position of dissatisfaction with the role of the mistress forms a child fear of war $(r=0.41$ at $p \leq 0.05)$. Fear of war is a transformed and socially conditioned fear of death, instability, the possibility of a sudden collapse and destruction of way of life.

7) Maternal fears associated with sexual function and attitude of "partnership" ( $r=-0.43$ at $p \leq 0.05$ ), fear of confined space $(r=0.51$ at $\mathrm{p} \leq 0.05)$. Therefore, if mother is satisfied with themselves, it increases their emotional contact and partnership with the child. Partnerships imply the equality in the family, the parents' adjusted relation to the child. Partnership results in the well-balanced development of the child's personality and the favorable climate in the family.

8) Actual fear of insanity ( $r=0.41$ at $p \leq 0.05)$, fear for the heart ( $r=0.44$ at $p \leq 0.05)$, fear of confined spaces ( $r$ $=0.42$ at $\leq 0.05)$, mother's fear of poverty $(r=-0.48$ at $p \leq 0.05)$ and parent attitude of development of the child's activity." Listed actual fears are nothing but the transformed fears of death. Mothers strive to develop the child as soon as possible, to teach him/her to be independent, while being anxious for their own health. The more the mother worries about the financial prosperity, the less they strive to develop the activity of the child. Child's progress involves his/her independence in condition of unstable financial situation; it becomes difficult for women managers to raise an active child. Activity development imposes certain responsibilities and obligations on the child, as well as the need to comply with the expectations of the parents. In that way, the child in respect of whom this attitude is formed, has a fear of war $(\mathrm{r}=0.40$ at $\mathrm{p} \leq 0.05)$. As it is known, a fear of war is a social fear of a threat to social contacts and a existence of a child as a person.

9) Fear of confined spaces and a fear of getting a disease ( $r=-0.50$ at $p \leq 0.05)$, and the "detachment of the husband" $(r=0.47$ at $p \leq 0.05)$. Fear of confined spaces is a feeling of inability to influence the situation or to change it somehow. "Detachment of the husband" causes a sense of insecurity, inability to change the situation; women do not feel support. Detachment of the husband in family relationships correlates with the formation of the child's fear of nightmares $(r=0.50 \mathrm{p} \leq 0.05)$. Instability and uncertainty between the spouses have a negative impact on the emotional condition of the child, which is reflected in the fear of frightening dreams. Relationship problems between spouses creates child's uncertainty and sense of insecurity resulting in a fear of pain $(r=0.47$ at $\mathrm{p} \leq 0.05$ ).

10) Fear of old age $(r=0.41$ at $p \leq 0.05)$ and "exam" fear $(r=0.39$ at $p \leq 0.05)$, and "mother's dependence". Both of these fears represent the transformed fear of responsibility. If a woman is afraid of monitoring, assessing, and responsibility in any form, she is going to experience difficulty in the independence manifestation. This attitude forms the child fear of fairy-tale characters $(\mathrm{r}=0.43$ at $\mathrm{p} \leq 0.05)$. Fairy tale characters break social norms and rules. The mother who feels her indecisiveness is unable to form the child's adequate and critical evaluation of social norms. "Dependent" mothers find it difficult to stick to any specific upbringing policy. As a result, the child develops divergent views about the standards and values. "Indecisiveness" of the mother is a negative feature in the emotional relations system in the mother-child diad. This violates the formation of the favorable climate in the relationship, which leads to the weakening of contact between mother and child (Božović, 1995; Astapov, 2004; Murtazina, Minullina, \& Frolova, 2014). 


\section{Discussions}

A significant place is given to the development of this problem in the writings and researches of both domestic and foreign psychologists. However, despite the large number of research problems in the scope of children and adults' fears, the parents' personalities, as well as the characteristics of the parental relationship; still the question of attitudes transferring the actual fears of parents (mothers) to their children remains hardly clarified. More and more women become the successful managers in different fields of work. Due to the lack of time for communication with their children, mothers have anxiety for them dramatically raised. The fears and anxiety of mothers (women leaders) are able to be expressed in family relations. A particular model of family relations (in the mother-child diad) can influence the formation of children's specific fears children (Minullina, Murtazina, \& Konyashina, 2014).

\section{Conclusion}

Thus, on the basis of the research conducted and results obtained we can draw the following conclusions. 1) The explanation of the fear phenomenon depends on specific features of a particular psychological school; 2) The structure of the actual fears of women leaders depends on the nature and specifics of their professional activity; 3 ) The actual fears of women in executive positions can be the source of their children's fears; 4) Fears transmitted to the child can manifest themselves in a transformed form; 5) Primary school age children fears can transform into socially mediated fears (attack, fire, flame, war and depth, fear of death and fear of parents' death); 6) Characteristics of parental attitudes of women leaders towards children include: the lack of autonomy and a sense of their self-sacrifice in the implementation of educational tactics, the desire, on the one hand to develop the activity of the child and to focus on partnership with him/her as soon as possible, and on the other hand, the tendency to suppress his will; 7) Formation and development of children's fears are indirectly featured by parental relationships.

In this way, the hypothesis put forward about the relationship of actual fears of women leaders and their children mediated by the characteristics of parental relationships has found its complete confirmation in the research conducted.

\section{Recommendations}

The results obtained can be used in educational and psychological practice for individual and family psychological counseling, psychotherapy, psychological support for children, for the organization of psychological and pedagogical work with parents (workshops, parental competence trainings, etc.) (Murtazina, Minullina, \& Frolova, 2014).

\section{Acknowledgments}

The work is performed according to the Russian Government Program of Competitive Growth of Kazan Federal University

\section{References}

Astapov, V. M. (2004). Children anxiety (p. 224). SPb, Piter.

Barbarisova, M. V., \& Shagivaleeva, G. R. (2013). Fear as a weakness and as a resource. Modern high technologies, 7(2), 195-195.

Božović, L. I. (1995). Problems of personality formation. In Selected works on psychology (p. 456). The Voronezh Institute of Practical Psychology.

Chirkina, S. E. (2015). Adults' meaning-making during vocational training. Review of European Studies, 7(4), 128-132. http://dx.doi.org/10.5539/res.v7n4p128

Icke, D. (1998). Fear. Freudian psychoanalytics conceptions. Encyclopedia of deep psychology, M., CC MG Management, 1, 800.

Martynenko, O. (2003). The origin of children fears. Journal of applied psychology, 2, 6-7.

Minullina, A. F., Murtazina, E. I., \& Konyashina, V. I. (2014). Structure and the relationship of topical fear among mothers and their children. Practical Medicine, 2(78), 88-96.

Mironenko, V. (1977). Readings in psychology (pp. 287-288). Tutorial. M.: Prosveshchenie.

Murtazina, E. I., Minullina, A. F., \& Frolova, A. V. (2014). Pedagogical Support Aimed to Form Future Pedagogue-Psychologists Readiness to Work with the Family. Middle-East Journal of Scientific Research, 20(8), 905-909. 
Panfilova, M. A. (1999). Fears in the little houses. Children and teenagers fears diagnosis. The School Psychologist, 8, 10-12.

Prikhozhan A. M. (2000). Children and teenagers anxiety: Psychological nature and age dynamics (p. 304). M.: Moscow psychological-social Institute.

Zakharov, A. I. (1986). Children and teenagers neuroses, The anamnesis, etiology and pathogenesis (p. 185). M.: Prosveshchenie.

Zakharov, A. I. (2005). Children fears at daytime and night (p. 332). SPb, Rech.

\section{Copyrights}

Copyright for this article is retained by the author(s), with first publication rights granted to the journal.

This is an open-access article distributed under the terms and conditions of the Creative Commons Attribution license (http://creativecommons.org/licenses/by/3.0/). 